Politik Ekonomik Kuram 2018, Cilt 2(1), 73-86

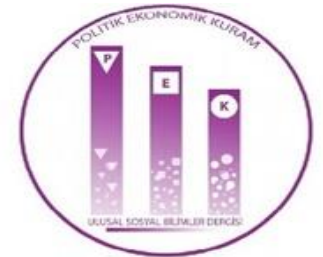

Politik Ekonomik Kuram Dergi Web Sitesi: http://dergipark.gov.tr/pek

Cilt 2(1) 2018

\title{
Hisse Senedi Piyasalarında Finansal Bağlantılılık Analizi ${ }^{1}$
}

\section{Onur POLAT}

\section{Makale Bilgileri}

Makale Geçmişi:

Makalenin Yüklendiği Tarih: 31.03.2018

Makalenin Kabul Edildiği Tarih: 06.04.2018

Jel Kodlar1: C3, G1, F3

Anahtar Kelimeler: Finansal Bağlantılılık, Finansal Bulaşıcılık, Yayılma Tablosu, Toplam Yayılma Endeksi,

\section{Özet}

Ülkeler arasındaki finansal bağlantılılık nedeniyle, finansal istikrarsızlık/çalkantı dönemlerinin bulaşıcı etkileri hızla yayılabilmektedir. Bu durum, küresel finansal piyasalar arası bağlantılılığın ölçülebilmesi ve anlaşılabilmesinin önemine işaret etmektedir. Bu çalışma, Diebold ve Yılmaz (2009, 2012) metodolojilerini kullanarak 9 ülke (G-7, Norveç ve Türkiye) finansal sistemleri arasındaki bağlantılılığı incelemektedir. Ek olarak, toplam yayılma endeksinin 200 -günlük kayan pencerelerdeki dinamiği bilinen finansal stres olaylarıyla verilmektedir.

Anahtar Kelimeler: Finansal Bağlantılılık, Finansal Bulaşıcılık, Yayılma Tablosu, Toplam Yayılma Endeksi,

\section{Financial Connectedness Analysis at the Stock Market}

\section{Abstract}

Thanks to the financial connectedness, contagion effects of financial instability/turmoil periods can quickly disperse. This situation indicates importance of measuring and understanding of connectedness of global financial markets. This study investigates financial connectedness of 9 countries (G-7, Norway and Turkey) using Diebold and Yilmaz (2009, 2012) methodologies. In addition, the dynamics of 200-day rolling windows of total spillover index with well-known financial stress events are given.

Keywords: Financial Connectedness, Financial Contagion, Spillover Table, Total Spillover Index.

\footnotetext{
${ }^{1} \mathrm{Bu}$ çalışma, Hacettepe Üniversitesi Sosyal Bilimler Enstitüsü İktisat Bölümü’nde Onur Polat yayınlanmış olan "The Impacts of Energy Price Shocks on Financial Stability" isimli doktora tezinden derlenmiştir.

2 Dr., onurpolat@hacettepe.edu.tr,opolat62@yahoo.com.
} 


\section{Giriş}

Finansal bağlantılılık ve bulaşıcılık uluslararası finans literatüründe önemli araştırma alanları haline gelmiştir. Bulgular finansal piyasalar arasındaki stres yayılmalarının (spillovers) finansal istikrarsızlık dönemlerinde yükseldiğini ortaya koymaktadır. Dolayısıyla; literatürde artan sayıda çalışma finansal piyasalar arasındaki bulaşıcılık ve bağlantılılığı finansal istikrarsızlık/kargaşa dönemlerinde ölçmeye çalışmaktadır.

Ülkeler arası finansal stres geçişi finansal istikrarsızlık dönemlerinde yükselmektedir. 2008 küresel finansal krizi bu duruma örnek teşkil etmektedir. 2008 küresel finansal krizi ABD’de eşik altı ipotekli konut kredilerine dayalı menkul kıymetleri içeren fonların çöküşüyle başlamış ve krizin bulaşıcı etkileri gelişmiş/gelişmekte olan ülkelere hızla yayılmıştır. Öte yandan 20102012 Avrupa borç krizi Yunanistan, Portekiz, İrlanda, İspanya, İtalya gibi çevre ve merkez Avrupa ülkelerinde finansal stresin önemli seviyelerde yükselmesine yol açmış ve krizin bulaşıcılık etkileri diğer ülkelerin finansal ve reel sistemlerine negatif olarak sirayet etmiştir.

Bu çalışmanın amacı; 9 ülkenin (G-7, Türkiye ve Norveç) hisse senedi piyasa endeksleri tarihsel oynaklıkları (realized volatility) arasındaki yayılmaları Diebold-Yılmaz (2009, 2012) metodolojilerini uygulayarak elde etmektir.

Çalışmanın yapısı şu şekildedir: Girişi izleyen ikinci bölümde ilgili literatürdeki çalışmalara yer verilmiştir. İzleyen üçüncü bölümde, çalışmada kullanılan veri ve metodoloji verilmektedir. Dördüncü bölüm ampirik sonuçları içermektedir. Beşinci ve son bölümde çalışmanın sonuçları tartış1lmaktadır.

\section{Literatür Taraması}

Finansal istikrarsızlık bulaşıcıdır ve oldukça entegre finansal piyasalar nedeniyle küresel boyutta hızla yayılabilir. Literatürde, krizin bulaşıcılık etkilerini inceleyen çalışmalar yer almaktadır. Bu çalışmalar finansal bulaşıcılığın stilize gerçekleri ifade etmektedir: Bulgular arasında; piyasalar arası eş-hareketlerin artması (Arestis vd., 2005; Aloui vd., 2011; Guo vd., 2011; Shen vd., 2015; Straetmans ve Chaudhry, 2015; Chang ve Cheng, 2016; Hemche vd., 2016), piyasa getiri korelasyonlarının yükselmesi (Chiang vd., 2007; Luchtenberg ve Vu, 
2015), hisse senedi piyasa şoklarının yayılması (Rigobon, 2003; Kenourgios ve Paltalidis, 2011), ekonomik bir şok esnasında veya sonrasında piyasa bağlantılarının yükselmesi (Claessens ve Forbes, 2001; Forbes ve Rigobon, 2002; Longstaff, 2010; Ahlgren ve Antell, 2010; Samarakoon, 2011), finansal piyasalar arasında yayılmaların oluşması (Celik, 2012; Dimitriou ve Kenourgios, 2013; Blatt vd., 2015; Chan vd., 2016) sayılabilir. Yaygın çalışmalarda kullanılan ekonometrik yöntemler, CCC-GARCH, DCC GARCH, GJR-GARCH (Gardini ve De Angelis, 2002; Arestis vd., 2005; Chiang vd., 2007; Phylaktis ve Xia, 2009; Celik, 2012; Moussa, 2014; Hemche vd., 2016), Granger Nedensellik (Luchtenberg ve Vu, 2015; Chang ve Cheng, 2016), Logit (Duggar ve Mitra, 2009; Markwat vd., 2009; Boyson vd., 2010), Markov Switching (Guo vd., 2011; Dimitriou ve Kenourgios, 2013), Multivariate Regime-Switching Gaussian Copula (Aloui vd., 2011; Kenourgios ve Paltalidis, 2011) ve VAR modelleri (Favero ve Giavazzi, 2002; Rigobon, 2003; Ahlgren ve Antell, 2010; Longstaff, 2010; Guo vd., 2011; Samarakoon, 2011) olarak ifade edilebilir.

Finansal bulaşıcılık çalışmaları ile birlikte, finansal bağlantılılık hakkında da geniş bir literatür bulunmaktadır. Finansal kargaşa/istikrarsızlık dönemlerinde piyasalar arasındaki yayılmalar yükseldiği için, araştırmacılar piyasalar arası bağlantılılığı ölçmeye çalışmıştır. Bu çalışmalar arasında; Diebold ve Yılmaz (2009), 19 ülkenin hisse senedi piyasaları arasındaki getiri ve oynaklık geçişlerini, VAR modelinden elde edilen tahmin hatası varyans ayrıştırmaları ile net, yönlü (directional) ve toplam yayılmaları (spillover) hesaplayarak bulmaktadır. Diebold ve Yılmaz yöntemi ile farklı piyasalar arasındaki yayılmalar hesaplanmaktadır (Diebold ve Y1lmaz, 2010, 2012, 2014 ve 2015).

Yukarıda ifade edilen finansal bağlantılılık çalışmalarında farklı bulgular elde edilmektedir. Örneğin, hisse senedi oynaklık yayılmalarının kriz dönemlerinde yükseldiği; fakat hisse senedi getiri oynaklıkları için böyle bir durumun olmadığı tespit edilmiştir (Diebold ve Yılmaz, 2009; Yı1maz, 2010). En yüksek net yönlü oynaklık yayılması hisse senedi piyasası için tespit edilirken, en yüksek toplam yönlü oynaklık yayılması tahvil piyasası için bulunmuştur (Diebold and Y1lmaz, 2012). Son küresel krizin patlama dönemlerinde daha yüksek yayılmalar bulunmuştur (Diebold and Y1lmaz, 2014). 2007-2008 döneminde yayılmalar ABD'den Avrupa piyasasına doğru tespit edilirken, 2011 Haziran'da yayılmaların ters yönde oluştuğu tespit edilmiştir (Diebold ve Y1lmaz, 2015). 
Diebold-Yılmaz yöntemi bir çok çalışma tarafından takip edilmiş ve finansal veya reel zaman serileri arasındaki yayılmalar hesaplanmıştır. Bunlar arasında; döviz piyasası çalışmaları: 3 merkez Avrupa ülkesi döviz kuru arasındaki 3 Ocak 2003 ile 30 Haziran 2009 dönemindeki yayılmalar (Çek Korunası (EUR/CZK), Macar Forinti (EUR/HUF) ve Polonya Zlotisi (EUR/PLN)), 4 döviz kuru arasındaki 6 Ocak 1986 ile 30 Aralık 2011 dönemindeki yayılmalar (ABD doları değişim oranı olarak Euro (EUR), Pound (GBP), Japon Yeni (JPY) ve İsviçre Frankı (CHF)), hisse senedi piyasası çalışmaları: 9 Asya ülkesi, Almanya ve ABD’nin hisse senedi piyasaları ve endüstri üretim endeksleri arasındaki 21 Temmuz 2005 ile 31 Ağustos 2010 dönemindeki yayılmalar (Fujiwara ve Takahashi, 20125 ülkenin (Fransa, Almanya, İngiltere, İsviçre ve Hollanda) hisse senedi piyasaları arasındaki 1 Ocak 2002 ile 29 Ağustos 2013 dönemindeki yayılmalar (Cipollini vd., 2013), 5 gelişmiş ülke (ABD, İngiltere, Almanya, Japonya ve Fransa) hisse senedi piyasaları arasındaki Ocak 1990 ile Mayıs 2013 dönemindeki yayılmalar (Tsai, 2014), 14 Asya ülkesinin hisse senedi piyasaları arasındaki Ocak 1996 ile Ekim 2015 dönemindeki yayılmalar (Guimaraes ve Hong, 2016) Diebold-Y1lmaz (D-Y) yöntemleriyle hesaplanmıştır.

Bu çalışmada, 9 ülkenin (G-7, Türkiye ve Norveç) finansal bağlantılılığı, bu ülkelerin hisse senedi piyasa endeksleri tarihsel oynaklıkları (volatility) arasındaki yayılmaları DieboldYılmaz $(2009,2012)$ yöntemleriyle hesaplanarak araştırılmaktadır. Ek olarak, toplam yayılma endeksinin dinamiği 200-günlük kayan pencerelerde bilinen finansal stress olaylarıyla verilmektedir.

\section{Metodoloji ve Veri}

Bu bölümde çalışmada kullanılan metodoloji ve veri kümesi ifade edilmektedir.

\subsection{Metodoloji}

Diebold and Yılmaz (2009) getiri ve oynaklık yayılmalarını VAR (Vektör Otoregresif- Vector Autoregression) modeli temelinde tanımlamaktadır. $N$-bileşenli standart VAR modelinde her bir $x_{i}$ varlığı $i=1, \ldots, N$ olmak üzere aşağıdaki şekilde ifade edilmektedir: 


$$
x_{t}=\sum_{i=1}^{q} \Phi_{i} x_{t-1}+\varepsilon_{t}
$$

burada $x_{t} N \times 1$ boyutlu varlık vektörünü, $\varepsilon_{t}, N \times 1$ i.i.d. hata terimlerini $\varepsilon_{t} \sim N(0, \Omega)$ ifade etmektedir.

VAR modelinin hareketli ortalama (moving average) gösterimi aşağıdaki gibidir:

$$
x_{t}=\sum_{i=1}^{\infty} \mathrm{A}_{i} \varepsilon_{t-i}
$$

$A_{i}=\sum \Phi_{j} A_{i-j}, j=1, \ldots, q$ olarak tanımlanmaktadır. Bu durumda, $\mathrm{H}$-adım-ön tahmin hatası varyans ayrıştırmaları (forecast error variance decompositions), $\theta_{i j}^{g}(H)$ aşağıdaki gibi tanımlanmaktadır:

$$
\theta_{i j}^{g}(H)=\frac{\sigma_{i i}^{-1} \sum_{h=0}^{H-1}\left(\mu_{i}^{\prime} A_{h} \Omega \mu_{j}\right)^{2}}{\sum_{h=0}^{H-1}\left(\mu_{i}^{\prime} A_{h} \Omega A_{h}^{\prime} \mu_{i}\right)}
$$

burada, $\sigma_{i i}, i$. hata teriminin standart sapmasını, $\Omega$ hata terimlerinin varyans vektörünü, $\mu_{i} i$. bileşenin seçimi için 1 diğer durmlarda 0 dır.. Bu durumda, her bir ön tahmin hatası varyans ayrıştırması aşağıdaki gibi normalleştirilmektedir:

$$
\tilde{\theta}_{i j}^{g}=\frac{\theta_{i j}^{g}(H)}{\sum_{i=1}^{N} \theta_{i j}^{g}(H)}
$$

Yukarıdaki tanımlar 1şı̆̆ında, Diebold and Yılmaz (2012) toplam, yönlü ve net yayılmaları aşağıdaki gii tanımlamıştır.

Toplam yayılma endeksi aşağıdaki gibidir:

$$
S^{g}(H)=\frac{\sum_{i, j=1, \neq i}^{N} \theta_{i j}^{g}(H)}{\sum_{i, j=1}^{N} \theta_{i j}^{g}(H)} 100
$$

- $\quad$ i piyasasına diğer $j$ piyasalarından gelen yönlü yayılma: 


$$
S_{i *}^{g}(H)=\frac{\sum_{j=1, j \neq i}^{N} \widetilde{\theta}_{i j}^{g}(H)}{\sum_{j=1}^{N} \widetilde{\theta}_{i j}^{g}(H)} 100
$$

(6)

- $\quad i$ piyasasından diğer $j$ piyasalarına doğru olan yönlü yayılma:

$$
S_{* i}^{g}(H)=\frac{\sum_{j=1, j \neq i}^{N} \widetilde{\theta}_{j i}^{g}(H)}{\sum_{j=1}^{N} \widetilde{\theta}_{j i}^{g}(H)} 100
$$

- Son olarak, $i$ piyasasından diğer $j$ piyasalarına doğru olan net yayılma:

$$
S_{i}^{g}(H)=S_{* i}^{g}(H)-S_{i *}^{g}(H)
$$

\subsection{Veri}

G-7 ülkeleri (ABD, İngiltere, Japonya, Almanya, Fransa, İtalya, Japonya), Türkiye ve Norveç hisse senedi piyasa endeksleri Bloomberg veri tabanından indirilmiştir ${ }^{3}$.

\section{Yayılma Tablosu, Toplam Yayılma Endeksi}

Ampirik analize geçmeden önce, 9 ülke hisse senedi piyasa endeksi tarihsel oynaklıklarının dinamikleri 1/1/1998-27/2/2018 döneminde aşağıdaki gibi verilmektedir.

\footnotetext{
${ }^{3}$ G-7, Türkiye ve Norveç'in hisse senedi piyasa endeksleri ve periyotları şu şekildedir: (ABD, (S\&P 500, 2/1/198027/2/2018); İngiltere, (FTSE100, 30/12/1983-27/2/2018); Japonya, (Nikkei 225, 2/1/1980-27/2/2018); Almanya, (DAX, 2/1/1980-27/2/2018); Fransa, (CAC, 9/7/1987-27/2/2018); İtalya, (FTSE MIB, 31/12/1997-27/2/2018); Kanada, (S\&P/TSX, 2/1/1980-27/2/2018); Türkiye, (XU100, 1/1/1988-27/2/2018); Norveç, (OSEBX, 2/1/199627/2/2018)).
} 


\section{Şekil 1. Hisse Senedi Piyasa Endeksi Tarihsel Oynaklıkları}

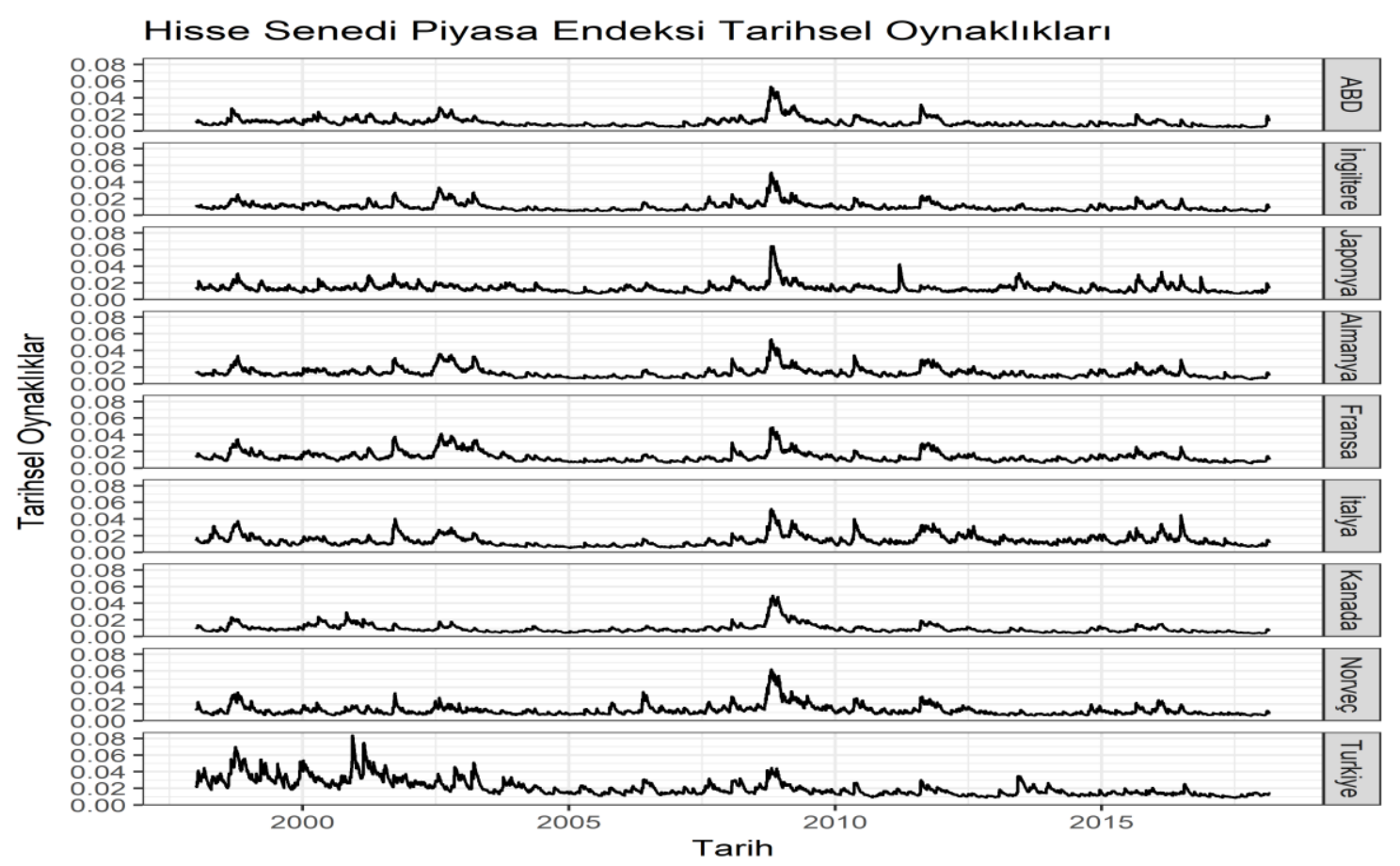

Şekil 1'den de görülebileceği gibi Türkiye hariç diğer ülkelerin hisse senedi piyasa endeksi tarihsel oynaklıkları 2008-2009 küresel finansal krizinde en yüksek değerlere ulaşmaktadır. Türkiye'nin hisse senedi piyasa endeksi tarihsel oynaklığı ise 2001-2002 döneminde yaşanmış olan ekonomik kriz nedeniyle en yüksek değerini almaktadır. 9 ülkenin hisse senedi piyasa endeksleri tarihsel oynaklıkları son dönemde (özellikle 2017 sonrası) yatay bir seyir izlemektedir.

Hisse senedi piyasa endeksleri arasındaki yayılmalar Diebold-Yılmaz (Diebold ve Yilmaz, 2012) metodolojisi kullanılarak elde edilmektedir. VAR analizi hisse senedi piyasa endeksi tarihsel oynaklıklarını ${ }^{4}$ içerecek şekilde yapılmaktadır. Klößner ve Wagner (2014) çalışması takip edilerek, VAR modeli için hassaslık analizi uygulanmış ve VAR derecesi 12 olarak belirlenmiştir ${ }^{5}$.

\footnotetext{
${ }^{4}$ Hisse senedi endeksi tarihsel oynaklıkları $\operatorname{GARCH}(1,1)$ ile elde edilmektedir. Durağan olan volatilite serileri $V A R$ analizinde kullanılmışlardır.

${ }^{5}$ VAR derecesi AIC (Akaike Information Criteria) ve FPE (Final Prediction Error)'a göre seçilmektedir.
} 
Hisse senedi piyasa endeksleri tarihsel oynaklıkları yayılma tablosu Tablo 1'de verilmektedir. Tablodaki $i$. satır ve $j$. sütun $i$ ülkesinden $j$ ülkesine doğru olan tahmini hata varyans katkısını ifade etmektedir. Dolayısıyla, tablo şu şekilde okunmalıdır: Örneğin, ABD’den İngiltere'ye doğru olan yayılma 2. satır 1 . sütunda verilen 32.88 değeridir.

Tablo 1. Yayılma Tablosu

\begin{tabular}{|l|l|l|l|l|l|l|l|l|l|l|l|}
\hline & ABD & İngiltere & Japonya & Almanya & Fransa & İtalya & Kanada & Norveç & Türkiye & $\begin{array}{l}\text { Diğerlerinden } \\
\text { Ÿ̈nlü }\end{array}$ \\
\hline ABD & 89,32 & 8,30 & 0,32 & 0,04 & 0,02 & 0,06 & 0,83 & 1,05 & 0,05 & 10.68 \\
\hline İngiltere & 32,88 & 64,91 & 0,38 & 0,07 & 0,11 & 0,04 & 0,85 & 0,74 & 0,02 & 35.09 \\
\hline Japonya & 11,93 & 11,84 & 73,96 & 0,06 & 0,72 & 0,06 & 0,86 & 0,47 & 0,10 & 26.03 \\
\hline Almanya & 32,27 & 45,48 & 0,84 & 20,12 & 0,41 & 0,13 & 0,53 & 0,22 & 0,01 & 79.87 \\
\hline Fransa & 30,82 & 34,60 & 1,09 & 10,40 & 21,57 & 0,06 & 1,10 & 0,27 & 0,07 & 78.42 \\
\hline İtalya & 24,92 & 30,57 & 1,43 & 13,06 & 1,09 & 28,14 & 0,42 & 0,35 & 0,02 & 71.86 \\
\hline Kanada & 40,48 & 9,71 & 0,34 & 0,09 & 0,13 & 0,09 & 47,69 & 1,33 & 0,15 & 52.31 \\
\hline Norveç & 23,00 & 23,60 & 0,55 & 1,13 & 0,12 & 0,23 & 3,60 & 47,63 & 0,14 & 52.37 \\
\hline Türkiye & 2,72 & 8,52 & 0,08 & 0,34 & 0,45 & 0,01 & 2,80 & 0,15 & 84,92 & 15.07 \\
\hline $\begin{array}{l}\text { Diğerlerine } \\
\text { Doğru Yönlü }\end{array}$ & 199,02 & 172,62 & 5,04 & 25,19 & 3,06 & 0,69 & 10,99 & 4,59 & 0,55 & \\
\hline $\begin{array}{l}\text { Kendisini } \\
\text { İçeren Yönlü }\end{array}$ & 288,34 & 237,53 & 79,01 & 45,31 & 24,63 & 28,82 & 58,67 & 52,22 & 85,47 & $\begin{array}{l}\text { Yopyllma } \\
\text { Endeksi = } \\
\text { Net Yayılma }\end{array}$ \\
\hline
\end{tabular}

Tablo 1'deki sonuçlara göre ABD'den diğer ülkelere doğru olan finansal risk geçişi en yüksek seviyededir. Dolayısıyla, ABD net finansal risk yayan ülke konumundadır. Bu durum, küresel finansal krizin ABD’de başlaması ve krizin bulaşıcı etkilerinin diğer ülkelere hızla yayılmasıyla açıklanabilir. İngiltere en yüksek finansal risk yayan 2. ülkedir. Brexit referandumu sırasında ve sonrasında İngiltere'den diğer ülkelere yüksek finansal risk geçişinin olması bu durumu açıklayabilir. Tablo 1'den çıkarılabilecek bir diğer sonuç, örneklemdeki Avrupa Parasal Birliği (APB, EMU) üyesi ülkeler (Almanya, Fransa ve İtalya) arasındaki yüksek seviyedeki finansal risk geçişleridir. Bununla birlikte, İngiltere'den EMU ülkelerine ve Norveç'e yüksek finansal yayılma gözlenmektedir. Almanya diğer ülkelerden net finansal risk alan ülke durumundadır. Bu duruma, İngiltere'den Almanya’ya doğru olan yüksek finansal risk geçişi neden olmaktadır. Türkiye diğer ülkelerden ve diğer ülkelere en düşük finansal risk geçişi olan ülke 
konumundadır. Toplam yayılma endeksi \% 46.9 dur. Bu durum 9 ülke hisse senedi piyasaları arasındaki yüksek bağlantılılığa işaret etmektedir.

Bir sonraki aşamada, Diebold-Yılmaz (2012) metodolojisi takip edilerek 200-günlük kayan pencerelerde toplam yayılma endeksi elde edilmektedir. Şekil 2, 200-günlük kayan pencerelerde toplam yayılma endeksini ve bilinen finansal stres olaylarını göstermektedir.

\section{Şekil 2. 200-günlük Kayan Pencerelerde Toplam Yayılma Endeksi ve Bilinen Finansal Stres Olayları}

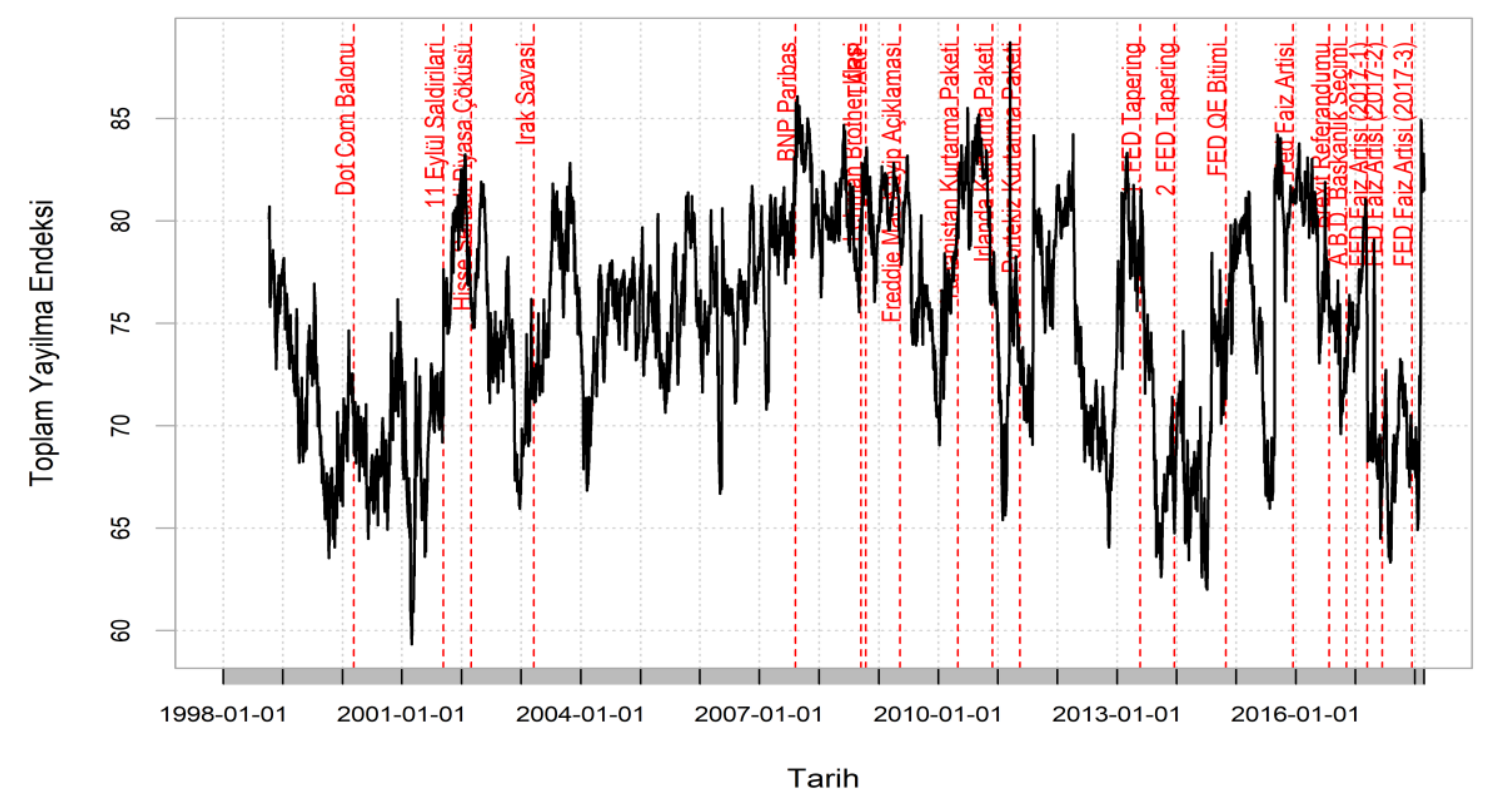

Şekil 2'den 200-günlük kayan pencerelerde toplam yayılma endeksinin (total spillover index) finansal stres olaylarına etkili bir şekilde tepki verdiği görülmektedir. Finansal stres olayları sırasıyla şu şekildedir: 10 Mart 2000, Dot-Com balonu; 11 Eylül 2001, terörist saldırılar; 1 Mart 2002, hisse senedi piyasası çöküşü; 20 Mart 2003, Irak savaşının başlaması; küresel finansal kriz olayları: 9 Ağustos 2007, BNP Paribas'ın eşik altı konut kredi fonlarından çekilmesi; 15 Ekim 2008, Lehman Brother's iflas başvurusu; 14 Ekim 2008 FED'in TARP (Troubled Asset Relief Program) açılaması; 29 Kasım 2009, Freddie Mac kayıp açıklaması; Avrupa borç krizi olayları: 2 Mayıs 2010, Yunanistan kurtarma paketi; 28 Kasım 2010, İrlanda kurtarma paketi; 17 Mayıs 2011, Portekiz kurtarma paketi; 22 Mayıs 2013, FED'in 1. Tapering açıklaması (tahvil alımlarını azaltma kararı alması); 18 Aralık 2013, FED'in 2. Tapering açıklaması; 29 Ekim 2014, FED’in NK'yi (Niceliksel Kolaylaştırma, Quantitative Easing) sonlandıracağını açıklaması; 16 Aralık 2015, FED faiz artışı (2006'dan itibaren ilk faiz artışı); 23 
Haziran 2016, Brexit referandumu; 8 Kasım 2016, ABD başkanlık seçimi ve FED'in 2017 yılında gerçekleştirdiği 3 faiz artışı (15 Mart, 14 Haziran ve 13 Aralık).

Toplam yayılma endeksi finansal istikrarsızlık/kriz dönemlerinde önemli ölçüde yükselmiştir. Avrupa borç krizi döneminde (yaklaşık olarak Portekiz kurtarma paketinin açıklanması) endeks maksimum değerine ulaşmıştır.

\section{Sonuç ve Değerlendirme}

Gelişmekte olan/gelişmiş ülkelerin finansal sistemlerinin yüksek etkileşime sahip olması finansal istikrarsılık/çalkantı dönemlerinde finansal stresin bulaşıcı etkilerinin hızla yayılmasına neden olabilir. 2008 küresel finansal krizi ve Avrupa borç krizi bu durumun örneklerini teşkil etmektedir. Dolayısıyla; ülkeler arası finansal bağlantılılığın tespit edilmesi/ölçülmesi bu bulaşıcı etkilerin azaltılması için son derece önemlidir. Bu bağlamda, çalışma 9 ülkenin finansal sistemleri arasındaki bağlantılılı̆̆ Diebold-Yılmaz (2012) metodolojisiyle ölçmeyi amaçlamıştır.

Çalışma 1. Adımda 9 ülkenin hisse senedi piyasa endeksleri tarihsel oynaklıkları arasındaki yayılmaları ve toplam yayılma endeksini elde etmiştir. Yayılma tablosu şu sonuçlara işaret etmektedir: i) 9 ülke arasında net finansal risk yayan ülke ABD'dir. Ve bu durum küresel finansal krizin ABD'de başlayıp bulaşıcı etkilerinin hızla diğer ülkelere yayılmasıyla paralellik taşımaktadır, ii) ikinci en yüksek net finansal risk yayılımına sahip olan ülke İngiltere'dir. Bu durum, Brexit referandumu sırasında ve sonrasında İngiltere'den diğer ülkelere (özellikle APB ve Avrupa ülkelerine) yüksek finansal risk geçişleri olmasıyla açıklanabilir, iii) örneklemdeki EMU ülkeleri arasında yüksek finansal risk geçişlerinin varlığı tespit edilmiştir, iv) Almanya diğer ülkelerden net finansal risk alan ülke durumundadır. Bu durum, örneklemdeki APB üyesi ülkelerin hisse senedi piyasaları arasındaki yüksek yayılmadan kaynaklanmaktadır.

2 adımda toplam yayılma endeksinin 200-günlük kayan pencerelerdeki dinamiği elde edilmiştir. Toplam yayılma endeksinin dinamiği, endeksin finansal istikrarsızlık/çalkantı dönemlerinde yüksek değerler aldığına ve bilinen finansal stres olaylarına etkili bir şekilde tepki verdiğine işaret etmektedir. 
Çalışmanın sonuçları ülkeler arası yüksek finansal bağlantılığın varlığını teyit etmekte ve şu politikayı önermektedir: Otoriteler ve politika yapıcılar sadece finansal istikrarı yerel bazda sağlamakla yükümlü olmamalı, aynı zamanda finansal piyasalar arasındaki sistemik stresin bulaşıcı etkilerinin ülkeler arası yüksek finansal bağlantılık nedeniyle hızla yayılacağını göz önünde bulundurarak küresel boyutta finansal istikrarı sağlayacak politikalar üretmelidir.

\section{Kaynakça}

Ahlgren, N., \& Antell, J. (2010). Stock market linkages and financial contagion: A cobreaking analysis. The Quarterly Review of Economics and Finance, 50(2), 157-166.

Aloui, R., Aïssa, M. S. B., \& Nguyen, D. K. (2011). Global financial crisis, extreme interdependences, and contagion effects: The role of economic structure? Journal of Banking \& Finance, 35(1), 130-141.

Antonakakis, N. (2012). Exchange return co-movements and volatility spillovers before and after the introduction of euro. Journal of International Financial Markets, Institutions and Money, 22(5), 1091-1109.

Antonakakis, N., \& Vergos, K. (2013). Sovereign bond yield spillovers in the Euro zone during the financial and debt crisis. Journal of International Financial Markets, 26, 258-272.

Arestis, P., Maria Caporale, G., Cipollini, A., \& Spagnolo, N. (2005). Testing for financial contagion between developed and emerging markets during the 1997 East Asian crisis. International Journal of Finance \& Economics, 10(4), 359-367.

Blatt, D., Candelon, B., \& Manner, H. (2015). Detecting contagion in a multivariate time series system: An application to sovereign bond markets in Europe. Journal of Banking \& Finance, 59, 1-13.

Bostanci, G., \& Yilmaz, K. (2015, 08 22). SSRN. doi:http://dx.doi.org/10.2139/ssrn.2647251

Boyson, N. M., Stahel, C. W., \& Stulz, R. M. (2010). Hedge fund contagion and liquidity shocks. The Journal of Finance, 65(5), 1789-1816.

Bubák, V., Kočenda, E., \& Žikeš, F. (2011). Volatility transmission in emerging European foreign exchange markets. Journal of Banking \& Finance, 35(11), 2829-2841.

Celik, S. (2012). The more contagion effect on emerging markets: The evidence of DCCGARCH model. Economic Modelling, 29(5), 1946-1959.

Chan, S., Han, G., \& Zhang, W. (2016). How strong are the linkages between real estate and other sectors in China? Research in International Business and Finance, 36, 52-72. 
Chang, G. D., \& Cheng, P. C. (2016). Evidence of cross-asset contagion in US markets. Economic Modelling, 58, 219-226.

Chiang, T. C., Jeon, B. N., \& Li, H. (2007). Dynamic correlation analysis of financial contagion: Evidence from Asian markets. Journal of International Money and finance, 26(7), 1206-1228.

Cipollini, A., Cascio, I. L., \& Muzzioli, S. (2015). Financial connectedness among European volatility risk premia. CEFIN. Modena: Centro Studi di Banca e Finanza.

Claessens, S., \& Forbes, K. (2001). International financial contagion: An overview of the issues and the book. In S. \&. Claessens, International financial contagion (pp. 3-17). New York: Springer .

Closa, C., \& Maatsch, A. (2014). In a spirit of solidarity? Justifying the European financial stability facility (EFSF) in national parliamentary debates. JCMS: Journal of Common Market Studies, 52(4), 826-842.

Csardi, G.; Nepusz, T. (2006). The igraph software package for complex network research. InterJournal, Complex Systems, 1695. Retrieved from http://igraph.org

Dancho, M.; Vaughan, D. (2017). timetk: A Tool Kit for Working with Time Series in R. Retrieved from https://CRAN.R-project.org/package=timetk

Diebold, F. X., \& Yilmaz, K. (2009). Measuring financial asset return and volatility spillovers, with application to global equity markets. The Economic Journal, 119(534), 158-171.

Diebold, F. X., \& Yilmaz, K. (2012). Better to give than to receive: Predictive directional measurement of volatility spillovers. International Journal of Forecasting, 28(1), 5766.

Diebold, F. X., \& Yilmaz, K. (2015). rans-Atlantic equity volatility connectedness: US and European financial institutions, 2004-2014. Journal of Financial Econometrics, 14(1), 81-127.

Diebold, Francis X., and Kamil Yilmaz. (2014). On the network topology of variance decompositions: Measuring the connectedness of financial firms. Journal of Econometrics, 182(1), 119-134.

Dimitriou, D., \& Kenourgios, D. (2013). Financial crises and dynamic linkages among international currencies. Journal of International Financial Markets, Institutions and Money, 26, 319-332.

Duggar, E., \& Mitra, S. (2009). External linkages and contagion risk in Irish banks. IMF Staff Papers, 56(4), 758-786. 
Favero, C. A., \& Giavazzi, F. (2002). Is the international propagation of financial shocks nonlinear?: Evidence from the ERM. Journal of International Economics, 57(1), 231-246.

Fujiwara, I., \& Takahashi, K. (2012). Asian Financial Linkage: Macro-Finance Dissonance. Pacific Economic Review, 17(1), 136-159.

Gardini, A., \& De Angelis, L. (2012). A statistical procedure for testing financial contagion. Statistica, 72(1), 37-61.

Guimaraes, Roberto F., and Gee Hee Hong. (2016). Dynamic Connectedness of Asian Equity Markets. IMF. Washington: International Monetary Fund.

Guo, F., Chen, C. R., \& Huang, Y. S. (2011). Markets contagion during financial crisis: A regime-switching approach. International Review of Economics \& Finance, 20(1), 95109.

Hemche, O., Jawadi, F., Maliki, S. B., \& Cheffou, A. I. (2016). On the study of contagion in the context of the subprime crisis: A dynamic conditional correlation-multivariate GARCH approach. Economic Modelling, 52, 292-299.

Kenourgios, D., Samitas, A., \& Paltalidis, N. (2011). Financial crises and stock market contagion in a multivariate time-varying asymmetric framework. Journal of International Financial Markets, Institutions and Money, 21(1), 92-106.

Kloessner, S.; Wagner, S. (2016). fastSOM: Calculation of Spillover Measures. Retrieved from http://CRAN.R-project.org/package=fastSOM

Klößner, S., \& Wagner, S. (2014). Exploring all VAR orderings for calculating spillovers? yes, we can!- a note on Diebold and Yilmaz (2009). Journal of Applied Econometrics, 29(1), 172-179.

Longstaff, F. A. (2010). The subprime credit crisis and contagion in financial markets. Journal of financial economics, 97(3), 436-450.

Luchtenberg, Kimberly F., and Quang Viet Vu. (2015). The 2008 financial crisis: Stock market contagion and its determinants. Research in International Business and Finance, 33, 178-203.

Markwat, T., Kole, E., \& Van Dijk, D. (2009). Contagion as a domino effect in global stock markets. Journal of Banking \& Finance, 33(11), 1996-2012.

Merton, R. C. (1973). An intertemporal capital asset pricing model. Econometrica: Journal of the Econometric Society, 867-887. 
Moussa, W. B. (2014). Bank stock volatility and contagion: an empirical investigation with application of multivariate garch models. Journal of Economic Development, 39(2), 124.

Nelson, C. R., \& Siegel, A. F. (1987). Pparsimonious modeling of yield curves. Journal of Business, 60(4), 473-489.

Pfaff, B. (2008). VAR, SVAR and SVEC Models: Implementation Within R Package vars. Journal of Statistical Software, 27(4), 1-32.

Phylaktis, K., \& Xia, L. (2009). Equity market comovement and contagion: A sectoral perspective. Financial Management, 38(2), 381-409.

Polat, O. (2017). The Impacts of Energy Price Shocks on Financial Stability. Economics. Ankara: Hacettepe University.

Rigobon, R. (2003). On the measurement of the international propagation of shocks: is the transmission stable? Journal of International Economics, 61(2), 261-283.

Samarakoon, L. P. (2011). Stock market interdependence, contagion, and the US financial crisis: The case of emerging and frontier markets. Journal of International Financial Markets, Institutions and Money, 21(5), 724-742.

Shen, P. L., Li, W., Wang, X. T., \& Su, C. W. (2015). Contagion effect of the European financial crisis on China's stock markets: Interdependence and pure contagion. Economic Modelling, 50, 193-199.

Straetmans, S., \& Chaudhry, S. M. (2015). Tail risk and systemic risk of US and Eurozone financial institutions in the wake of the global financial crisis. Journal of International Money and Finance, 58, 192-223.

Tsai, I. C. (2014). Spillover of fear: Evidence from the stock markets of five developed countriesInternational Review of Financial Analysis. International Review of Financial Analysis, 33, 281-288.

Yilmaz, K. (2010). Return and volatility spillovers among the East Asian equity markets. Journal of Asian Economics, 21(3), 304-313. 